\title{
Ketamine and midazolam as procedural sedation in children: a structured literature review and narrative synthesis
}

\author{
P Reddy,' (iD) M Ramburuth,' (iD) RN Rodseth ${ }^{2,3}$ (i) \\ ${ }^{1}$ Department of Anaesthesiology, Nelson R Mandela School of Medicine, University of KwaZulu-Natal, Durban, South Africa \\ ${ }^{2}$ Department of Anaesthesia, University of KwaZulu-Natal, Pietermaritzburg, South Africa \\ ${ }^{3}$ Drs Jones Bhagwan and Partners, Pietermaritzburg, South Africa \\ Corresponding author, email: rodsethr@ukzn.a.c.za
}

In paediatric patients the alleviation of preoperative anxiety is key to ensuring a smooth anaesthetic, and studies have shown that a pleasant induction is able to prevent adverse postoperative behavioural changes. Oral midazolam and ketamine in combination have been used as premedication to ameliorate this anxiety, but the utility of this combination remains unclear. The authors conducted a systematic review and narrative synthesis of randomised controlled trials testing the effectiveness of the combination of oral midazolam and ketamine versus midazolam alone as preanaesthetic sedation in children aged one to 15 years of age undergoing elective paediatric surgery. Ten trials were included in this analysis. Trials using combinations of midazolam ( 0.25 to $0.3 \mathrm{mg}^{\mathrm{kg}} \mathrm{j}^{-1}$ ) and ketamine ( 2 to $3 \mathrm{mg} \cdot \mathrm{kg}^{-1}$ ) provided higher quality sedation with a similar or better side-effect profile than midazolam $0.5 \mathrm{mg}^{\mathrm{kg}} \mathrm{g}^{-1}$ alone, without prolonging recovery time.

\section{Introduction}

In paediatric patients the alleviation of preoperative anxiety is a key part of ensuring a smooth anaesthetic.' Studies have shown that a pleasant induction is able to ameliorate adverse postoperative behavioural changes, e.g. temper tantrums, enuresis, general anxiety. ${ }^{1} \mathrm{~A}$ wide range of techniques and medications have been used with varying degrees of success..$^{2,3}$

One of these approaches has been the combination of oral midazolam and ketamine (MIKE), which is thought to lower the total dose of each drug required for adequate sedation and result in fewer adverse effects than when the drugs are used individually. ${ }^{4}$ Numerous studies evaluating this combination have been conducted. ${ }^{4-10}$ The authors sought to conduct a structured literature review and narrative synthesis to determine the efficacy and possible adverse effects of this combination when used as a premedication in paediatric patients undergoing elective surgery compared with midazolam alone as a premedication.

\section{Methods}

Although not a meta-analysis, the authors followed the Preferred Reporting Items for Systematic Reviews and MetaAnalysis (PRISMA) guidelines when conducting this study. ${ }^{11}$ All published randomised controlled trials that used oral MIKE as preanaesthetic sedation and compared this to midazolam on its own, in children aged one to 15 years of age undergoing elective surgery, were included in the study. Trials were excluded if they had a cluster, non-inferiority, or a factorial design, or were pilot trials.

The following electronic databases were searched on 12 February 2019: Pubmed, Scopus, Web of Science and the Cochrane database. No date limitations were placed on any of the searches. The authors used the following Medical Subject
Headings (MESH) terms to conduct the search: "preanaesthetic medication", "ketamine" and "midazolam". These were used in the following combination [(ketamine AND midazolam) AND (preanaesthetic medication)].

Two investigators (PR and MR) independently screened the titles and abstracts of each citation identified from the search results to determine whether they met the eligibility criteria. All citations suspected of possibly meeting the eligibility criteria were identified and a full text evaluation of each paper was performed. Chance corrected inter-observer screening agreement for trial eligibility was tested using the kappa statistic. All full text reviews were independently conducted by PR and MR and then discussed to ensure a consensus was reached. Where consensus could not be reached, a third investigator, RR acted as an adjudicator to resolve disagreements.

For each eligible trial the following data were extracted: author, year of publication, sample size, age range of study group, sex, ketamine dose, midazolam dose, comparator drug and dose, type of surgery, type of anaesthetic, primary sedation assessment tool used, the recorded level of sedation at the time of induction, and any adverse outcomes associated with the premedication. The authors compared MIKE versus midazolam given as a premedication. The authors did not examine trials that compared MIKE given in combination against a placebo, or against any other type of preoperative sedative. The authors chose the assessment of patient mask acceptance or tolerance, or venous cannula insertion as the primary outcome of interest for this study. Where these were not recorded the authors reported the particular study outcome reported as being closest to the time of induction or initiation of surgery. The quality of each included trial was assessed using the measures contained in the Cochrane risk of bias tool. 
To facilitate a narrative synthesis the authors classified the MIKE regimens as high (midazolam $\geq 0.5 \mathrm{mg}^{\mathrm{kg}}{ }^{-1}$ and ketamine $>4 \mathrm{mg}^{\mathrm{kg}}{ }^{-1}$ ), intermediate (midazolam 0.5 to $0.4 \mathrm{mg} \cdot \mathrm{kg}^{-1}$ and ketamine $\leq 4 \mathrm{mg} \cdot \mathrm{kg}^{-1}$ ) or low (midazolam $\leq 0.3 \mathrm{mg}^{\mathrm{kg}}{ }^{-1}$ and ketamine $\leq 3 \mathrm{mg}^{\mathrm{kg}} \mathrm{k}^{-1}$ ) dose.

\section{Results}

The authors identified 182 trials, of which 38 underwent full text review. Subsequently, 28 trials were excluded leaving 10 eligible trials that underwent data extraction and analysis (Figure 1). The kappa statistic for agreement between trial eligibility was good (0.7). The characteristics of the included trials are detailed in Table I. Table II describes the tools used to assess adequacy of sedation at the time of, or closest to, induction or initiation of surgery. Most trials reported patient mask acceptance at the time of induction as an outcome, two trials assessed sedation at the time of venepuncture, ${ }^{9,12}$ and one trial the time to reach a postoperative Aldrete score $\geq 9$ in recovery. ${ }^{10}$ The quality of the included trials, which were generally high, are reported in Table III.

Table IV summarises the results of each of the included trials, focusing on the selected primary outcomes. In general, the combination of midazolam and ketamine resulted in improved sedation at the time of induction as compared to midazolam alone.

Table I: Characteristics of trials included in the systematic review of the efficacy of oral combination midazolam and ketamine compared against oral midazolam as procedural sedation in children one to 15 years of age undergoing elective surgery

\begin{tabular}{|c|c|c|c|c|c|c|c|}
\hline Author, year & $\begin{array}{l}\text { Sample } \\
\text { size }\end{array}$ & $\begin{array}{l}\text { Age range } \\
\text { (years) }\end{array}$ & $\begin{array}{l}\text { Sex } \\
(M / F)\end{array}$ & $\begin{array}{l}\text { Midazolam/ketamine dose } \\
\text { in }{\mathrm{mg} \cdot \mathrm{kg}^{-1}}^{-1}\end{array}$ & $\begin{array}{l}\text { Midazolam dose } \\
\text { in } \text { mg.kg-1 }^{-1}\end{array}$ & Anaesthetic & Surgery \\
\hline Astuto, $2002^{13}$ & 120 & $2-6$ & $23 / 97$ & $\begin{array}{l}0.3 / 1(n=40) \\
0.3 / 2(n=42)\end{array}$ & $0.5(n=38)$ & General & Minor \\
\hline $\begin{array}{l}\text { Banerjee, } \\
2011^{4}\end{array}$ & 60 & $1-7$ & $\mathrm{~N} / \mathrm{A}$ & $0.25 / 2.5(n=30)$ & $0.5(n=30)$ & General & Plastic, urological \\
\hline $\begin{array}{l}\text { Barkan, } \\
2014^{5}\end{array}$ & 60 & $1-10$ & $32 / 28$ & $0.5 / 5(n=30)$ & $0.5(n=30)$ & Local & Plastic \\
\hline $\begin{array}{l}\text { Baygin, } \\
2010^{6}\end{array}$ & 30 & $5-8$ & $20 / 10$ & $0.25 / 3(n=15)$ & $0.7(n=15)$ & Local and $\mathrm{N}_{2} \mathrm{O}$ & Dental \\
\hline $\begin{array}{l}\text { Darlong, } \\
2004^{8}\end{array}$ & 48 & $1-9$ & $36 / 12$ & $0.25 / 3(n=24)$ & $0.5(n=24)$ & General & Ophthalmic \\
\hline $\begin{array}{l}\text { Darlong, } \\
2011^{7}\end{array}$ & 87 & $1-10$ & $64 / 23$ & $\begin{array}{l}0.25 / 3(n=29) \\
0.5 / 6(n=29)\end{array}$ & $0.5(n=29)$ & General & Ophthalmic \\
\hline $\begin{array}{l}\text { Funk, } \\
2000^{9}\end{array}$ & 80 & $2-10$ & $50 / 63$ & $0.5 / 3(n=40)$ & $0.5(n=40)$ & General & Dental, ENT, plastic \\
\hline $\begin{array}{l}\text { Kulikov, } \\
2010^{12}\end{array}$ & 100 & $2-10$ & $53 / 47$ & $0.5 / 3(n=80)$ & $0.75(n=20)$ & General & Neuro \\
\hline $\begin{array}{l}\text { Trabold, } \\
2002^{10}\end{array}$ & 79 & $1-8$ & $\mathrm{~N} / \mathrm{A}$ & $\begin{array}{l}0.5 / 1.8(n=25) \\
0.5 / 3(n=27)\end{array}$ & $0.5(n=27)$ & General & Ophthalmic, plastic \\
\hline $\begin{array}{l}\text { Warner, } \\
1995^{14}\end{array}$ & 40 & $1.5-7$ & $\mathrm{~N} / \mathrm{A}$ & $0.4 / 4(n=20)$ & $0.5(n=20)$ & General & Minor out-patient \\
\hline
\end{tabular}

ENT - ear, nose and throat; $M$ - male; F - female; N/A - not available

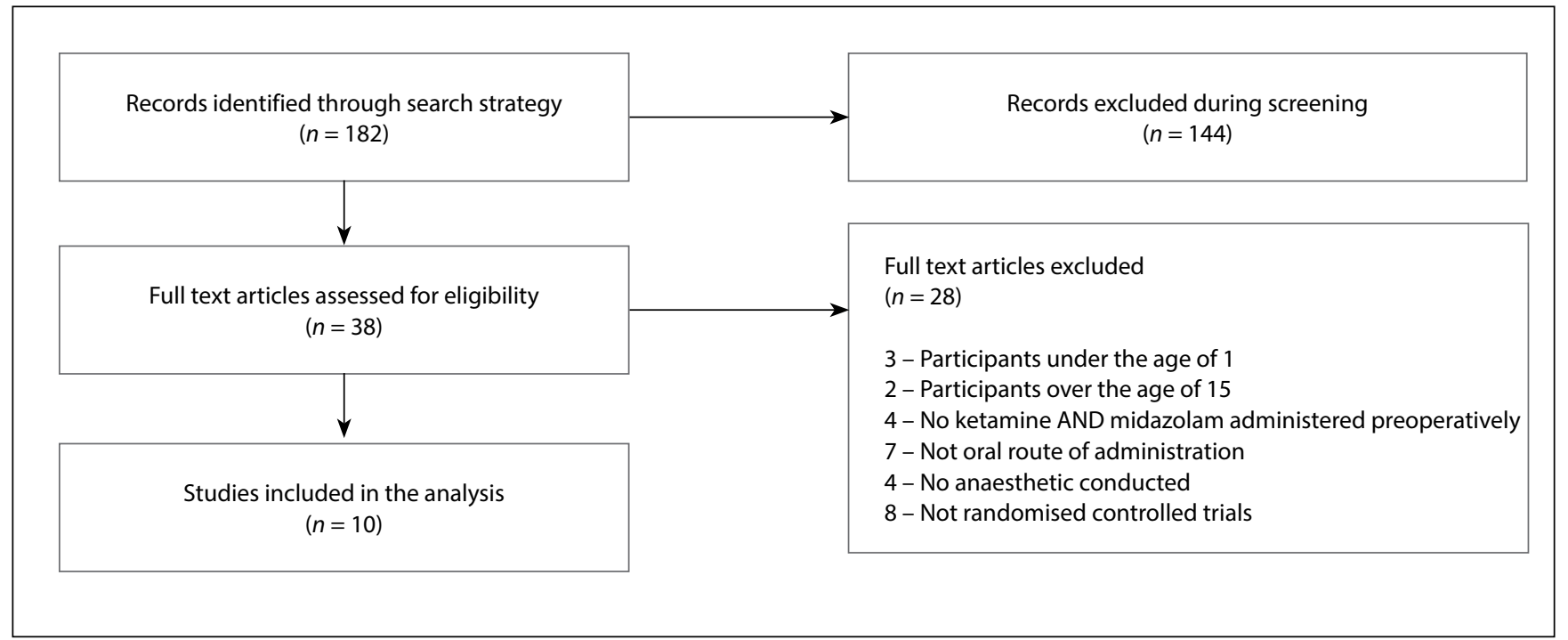

Figure 1: Flow diagram illustrating the trial selection process followed during the systematic review of the efficacy of oral combination midazolam and ketamine compared against oral midazolam as procedural sedation in children one to 15 years of age undergoing elective surgery 
Table II: Primary sedation assessment tools used in trials included in the systematic review of the efficacy of oral combination midazolam and ketamine compared against oral midazolam as procedural sedation in children one to 15 years of age undergoing elective surgery

\begin{tabular}{|c|c|c|c|}
\hline Author, year & Assessment tool & Time of assessment & Validated tool \\
\hline Astuto, $2002^{13}$ & $\begin{array}{l}\text { Sedation 4-point scale [alert to asleep] } \\
\text { Anxiolysis 4-point scale [combative to friendly] } \\
\text { Mask acceptance 4-point scale [combative to asleep] }\end{array}$ & Induction & No \\
\hline Banerjee, $2011^{4}$ & $\begin{array}{l}\text { Sedation 4-point scale [agitated to asleep] } \\
\text { Anxiolysis 4-point scale [combative to calm] } \\
\text { Mask acceptance 4-point scale [poor to excellent] }\end{array}$ & Induction & No \\
\hline Barkan, $2014^{5}$ & Sedation 5-point scale [barely arousable to agitated] & Initiation of surgery & No \\
\hline Baygin, $2010^{6}$ & Ramsay 6-point sedation scale [anxious to unresponsive to stimuli] & Induction & Yes \\
\hline Darlong, $2004^{8}$ & Mask acceptance 4-point scale [fear to ready acceptance] & Induction & No \\
\hline Darlong, $2011^{7}$ & Mask acceptance 4-point scale [fear to ready acceptance] & Induction & No \\
\hline Funk, $2000^{9}$ & Venepuncture tolerance 4-point scale [fight to no reaction] & Venepuncture & No \\
\hline Kulikov, $2010^{12}$ & Venepuncture tolerance 3-point scale [excessive to no movement] & Venepuncture & No \\
\hline Trabold, $2002^{10}$ & Aldrete score $\geq 9$ & Recovery & Yes \\
\hline Warner, $1995^{14}$ & Mask acceptance 5-point scale [Deep sleep to agitation] & Induction & No \\
\hline
\end{tabular}

Table III: Methodological quality and risk of bias of trials included in the systematic review of the efficacy of oral combination midazolam and ketamine compared against oral midazolam as procedural sedation in children one to 15 years of age undergoing elective surgery

\begin{tabular}{|c|c|c|c|c|c|c|}
\hline Author, date & $\begin{array}{c}\text { Random sequence } \\
\text { generation }\end{array}$ & $\begin{array}{c}\text { Allocation } \\
\text { concealment }\end{array}$ & $\begin{array}{l}\text { Participants and } \\
\text { personnel blinded }\end{array}$ & $\begin{array}{c}\text { Outcome assessment } \\
\text { blinded }\end{array}$ & $\begin{array}{l}\text { Incomplete } \\
\text { data }\end{array}$ & $\begin{array}{c}\text { Selective reporting } \\
\text { bias }\end{array}$ \\
\hline $\begin{array}{l}\text { Astuto, } \\
2002^{13}\end{array}$ & Yes & Yes & No & Yes & Yes & No \\
\hline $\begin{array}{l}\text { Banerjee, } \\
2011^{4}\end{array}$ & Yes & Yes & Yes & Yes & No & No \\
\hline $\begin{array}{l}\text { Barkan, } \\
2014^{5}\end{array}$ & Yes & Yes & Yes & Yes & No & No \\
\hline $\begin{array}{l}\text { Baygin, } \\
2010^{6}\end{array}$ & Yes & Yes & Yes & Yes & Yes & No \\
\hline $\begin{array}{l}\text { Darlong, } \\
2004^{8}\end{array}$ & Yes & Yes & Yes & Yes & No & No \\
\hline $\begin{array}{l}\text { Darlong, } \\
2011^{7}\end{array}$ & Yes & Yes & Yes & Yes & No & No \\
\hline $\begin{array}{l}\text { Funk, } \\
2000^{9}\end{array}$ & Yes & Yes & Yes & Yes & Yes & No \\
\hline $\begin{array}{l}\text { Kulikov, } \\
2010^{12}\end{array}$ & Yes & Yes & No & No & Yes & Yes \\
\hline $\begin{array}{l}\text { Trabold, } \\
2002^{10}\end{array}$ & Yes & Yes & Yes & Yes & No & Yes \\
\hline $\begin{array}{l}\text { Warner, } \\
1995^{14}\end{array}$ & Yes & Yes & Unclear & Yes & No & Yes \\
\hline
\end{tabular}

Analysis of the trials as using a high (midazolam $\geq 0.5 \mathrm{mg} \cdot \mathrm{kg}^{-1}$ and ketamine $>4 \mathrm{mg}^{\mathrm{kg}}{ }^{-1}$ ), ${ }^{5,7}$ intermediate (midazolam 0.5 to $0.4 \mathrm{mg} \cdot \mathrm{kg}^{-1}$ and ketamine $\leq 4 \mathrm{mg} \cdot \mathrm{kg}^{-1}$ ), $, 10,12,14$ or low (midazolam $\leq 0.3 \mathrm{mg} \cdot \mathrm{kg}^{-1}$ and ketamine $\left.\leq 3 \mathrm{mg} \cdot \mathrm{kg}^{-1}\right)^{4,6,8,13}$ dose regimen provided a useful framework from which to determine an optimal MIKE dosing strategy.

Trials using high doses of ketamine (> $4 \mathrm{mg}^{\mathrm{kg}}{ }^{-1}$ ) with midazolam, while having greater levels of sedation as compared to midazolam alone, showed the longest time to recovery as well as the greatest number of complications. Both the studies by Barkan ${ }^{5}$ and Darlong ${ }^{7}$ used a dose of 0.5 mg. $\mathrm{kg}^{-1}$ of midazolam and high ketamine doses of 5 and $6 \mathrm{mg}^{-\mathrm{kg}^{-1}}$ respectively. This led to significantly prolonged recovery times in the high dose ketamine MIKE group - 187 min (SD 93.1) for Barkan ${ }^{5}$ and 52 min (SD 21.9) for Darlong. ${ }^{7}$ These high dose ketamine MIKE studies also had a significant incidence of complications with Darlong reporting a $48 \%$ incidence of PONV and a $31 \%$ incidence of hypersalivation, ${ }^{7}$ while Barkan had a general complication rate of $19 \% .^{5}$

Trials using intermediate doses of ketamine (3-4 mg.kg-1) with midazolam seemed to have a similar rate of complications as compared to midazolam alone. Funk et al. compared midazolam $0.5 \mathrm{mg} \cdot \mathrm{kg}^{-1}$ and ketamine $3 \mathrm{mg} \cdot \mathrm{kg}^{-1}$ against midazolam $0.5 \mathrm{mg} \cdot \mathrm{kg}^{-1} .^{9}$ There was no difference in the time to discharge between MIKE (72 min, standard deviation [SD] 33) and midazolam alone (71 min, SD 28). Side-effects were similar in the MIKE group as compared to midazolam for the outcomes 
Table IV: Outcomes of trials included in the systematic review of the efficacy of oral combination midazolam and ketamine compared against oral midazolam as procedural sedation in children one to 15 years of age undergoing elective surgery

\begin{tabular}{|c|c|c|c|c|}
\hline $\begin{array}{l}\text { Dosing } \\
\text { regimen }\end{array}$ & Author, year & $\begin{array}{l}\text { Midazolam dose } \\
\quad\left(\mathrm{mg}^{\mathrm{kg}} \mathbf{k}^{-1}\right)\end{array}$ & $\begin{array}{l}\text { Midazolam/ketamine } \\
\text { dose }\left(\mathbf{m g} \cdot \mathbf{k g}^{-1}\right)\end{array}$ & Trial outcomes \\
\hline \multirow[b]{2}{*}{ High dose } & Barkan, $2014^{5}$ & $0.5(n=30)$ & $0.5 / 5(n=30)$ & $\begin{array}{l}\text { Deeper sedation at time of induction in MIKE group } \\
\text { (sedation score } 3.5, \text { SD } 0.67 \text { vs. } 2.26, \text { SD } 0.89 ; p=0.001 \text { ). }\end{array}$ \\
\hline & Darlong, $2011^{7 *}$ & $0.5(n=29)$ & $0.5 / 6(n=29)$ & $\begin{array}{l}\text { No difference in face mask acceptance. Longer emergence } \\
\text { time in MIKE group ( } 52 \mathrm{~min}, \mathrm{SD} 21.9 \text { ) vs. midazolam alone } \\
\text { ( } 36 \mathrm{~min}, \mathrm{SD} 12.1 ; p<0.001 \text { ). }\end{array}$ \\
\hline \multirow{5}{*}{$\begin{array}{l}\text { Intermediate } \\
\text { dose }\end{array}$} & Funk, $2000^{9}$ & $0.5(n=40)$ & $0.5 / 3(n=40)$ & $\begin{array}{l}\text { Improved sedation scores for anxiolysis and parental } \\
\text { separation with MIKE vs. midazolam alone }(p<0.05) \text {. } \\
\text { No statistical difference in time to extubation or discharge } \\
\text { from recovery. }\end{array}$ \\
\hline & Kulikov, $2010^{12}$ & $0.75(n=20)$ & $0.5 / 3(n=80)$ & $\begin{array}{l}\text { No difference in anxiolysis or movement on IV cannula } \\
\text { insertion }(p>0.05) \text {. }\end{array}$ \\
\hline & & & $0.5 / 1.8(n=25)$ & \multirow{2}{*}{$\begin{array}{l}\text { Faster discharge from recovery (Aldrete score } \geq 9 \text { ) with } \\
\text { midazolam ( } 39 \mathrm{~min}, \mathrm{SD} 23 \text { ) vs. MIKE groups with low dose } \\
\text { ketamine ( } 51 \mathrm{~min}, \mathrm{SD} 37 \text { ) and higher dose ketamine ( } 54 \mathrm{~min} \text {, } \\
\text { SD 24) but was not statistically significant }(p=0.145) .\end{array}$} \\
\hline & Trabold, $2002^{10}$ & $0.5(n=27)$ & $0.5 / 3(n=27)$ & \\
\hline & Warner, $1995^{14}$ & $0.5(n=20)$ & $0.4 / 4(n=20)$ & $\begin{array}{l}\text { Mask acceptance better with MIKE at } 85 \% \text { vs. } 42 \% \text { with } \\
\text { midazolam ( } 85 \% \text { vs } 42 \%) \text {. Parental separation was a } 100 \% \\
\text { successful in the MIKE group. }\end{array}$ \\
\hline \multirow{6}{*}{ Low dose } & & & $0.3 / 1(n=40)$ & \multirow{2}{*}{$\begin{array}{l}\text { Patients receiving midazolam } 0.3 \mathrm{mg} \cdot \mathrm{kg}^{-1} \text { and ketamine } \\
2 \mathrm{mg}^{\mathrm{kg}} \mathrm{g}^{-1} \text { had better mask acceptance compared to other } \\
\text { groups }(p=0.05) .\end{array}$} \\
\hline & Astuto, $2002^{13}$ & $0.5(n=38)$ & $0.3 / 2(n=42)$ & \\
\hline & Banerjee, $2011^{4}$ & $0.5(n=30)$ & $0.25 / 2.5(n=30)$ & No significant difference with face mask acceptance. \\
\hline & Baygin, $2010^{6}$ & $0.7(n=15)$ & $0.25 / 3(n=15)$ & $\begin{array}{l}\text { Deeper sedation at time of induction in MIKE group } \\
(p=0.046) \text {. }\end{array}$ \\
\hline & Darlong, $2004^{8}$ & $0.5(n=24)$ & $0.25 / 3(n=24)$ & $\begin{array}{l}\text { No significant difference in induction scores. } \\
\text { MIKE group showed faster emergence ( } 23 \mathrm{~min}, \text { SD } 5.6 \mathrm{vs} \text {. } \\
36 \mathrm{~min}, \mathrm{SD} 11.7, p<0.001 \text { ). }\end{array}$ \\
\hline & Darlong, $2011^{7 *}$ & $0.5(n=29)$ & $0.25 / 3(n=29)$ & $\begin{array}{l}\text { No difference in face mask acceptance. Faster emergence in } \\
\text { MIKE group ( } 22 \mathrm{~min}, \mathrm{SD} 5.7 \text { ) vs. midazolam alone ( } 36 \mathrm{~min}, \mathrm{SD} \\
12.1 ; p<0.001) \text {. }\end{array}$ \\
\hline
\end{tabular}

* Trial reported twice to facilitate dosage classification.

High dose - midazolam $\geq 0.5$ mg.kg ${ }^{-1}$ and ketamine $>4$ mg.kg ${ }^{-1}$, Intermediate dose - midazolam 0.4 to $0.5 \mathrm{mg} \cdot \mathrm{kg}^{-1}$ and ketamine $\leq 4 \mathrm{mg} \cdot \mathrm{kg}^{-1}$, Low dose $-\mathrm{midazolam} \leq 0.3 \mathrm{mg} \cdot \mathrm{kg}^{-1}$ and ketamine $\leq 3$ mg.kg-1.

MIKE - midazolam and ketamine; SD - standard deviation; IV - intravenous.

of vertigo ( $5 \%$ vs. $2.6 \%)$, psychedelic symptoms ( $8 \%$ vs. $8 \%$ ), salivation (18\% vs. $16 \%$ ) and excitation ( $0 \%$ vs. $3 \%$ ) respectively. Warner et al., using midazolam $0.4 \mathrm{mg}^{\mathrm{kg}}{ }^{-1}$ and ketamine $4 \mathrm{mg}^{\mathrm{kg}}{ }^{-1}$, reported no psychological disturbances in the MIKE group but did not comment on the incidence of hypersalivation or PONV. ${ }^{14}$ In the trial by Kulikov et al. the combination of midazolam 0.5 mg. $\mathrm{kg}^{-1}$ and ketamine $3 \mathrm{mg} \cdot \mathrm{kg}^{-1}$ showed higher quality sedation as compared to midazolam $0.75 \mathrm{mg} \cdot \mathrm{kg}^{-1}$ but did not report on any side-effects. ${ }^{12}$ Trabold et al. compared two MIKE groups of midazolam $0.5 \mathrm{mg} \cdot \mathrm{kg}^{-1}$ with ketamine $1.8 \mathrm{mg} \cdot \mathrm{kg}^{-1}$ and ketamine $3 \mathrm{mg} \cdot \mathrm{kg}^{-1}$ against midazolam $0.5 \mathrm{mg} \cdot \mathrm{kg}^{-1}$. In this trial the time to an Aldrete score $\geq 9$ in recovery was shorter in the midazolam alone group (39 $\mathrm{min}, \mathrm{SD} 23$ ) as compared to both the low dose ketamine (51 min, SD 37) and high dose ketamine (54 min, SD 24) MIKE groups, but was not statistically significant $p=0.145) .{ }^{10}$ No side-effects were reported in this study.

Trials using low dose regimens (midazolam $\leq 0.3 \mathrm{mg} \cdot \mathrm{kg}^{-1}$ and ketamine $\leq 3 \mathrm{mg} \cdot \mathrm{kg}^{-1}$ ) not only provided higher quality sedation than midazolam alone but had a similar or better sideeffect profile. Astuto et al., testing midazolam $0.3 \mathrm{mg} . \mathrm{kg}^{-1}$ with two doses of ketamine ( 1 and $\left.2 \mathrm{mg}^{\mathrm{kg}}{ }^{-1}\right)$ against midazolam
$0.5 \mathrm{mg} \cdot \mathrm{kg}^{-1}$, found optimal sedation conditions with ketamine $2 \mathrm{mg} \mathrm{kg}^{-1}$ but with the side-effects of nausea and vomiting (5\%), diplopia (5\%) and hallucinations (2.5\%) which were not seen in the lower dose ketamine group or in the midazolam alone group. ${ }^{13}$ Banerjee et al., testing midazolam $0.25 \mathrm{mg}^{\mathrm{kg}}{ }^{-1}$ with ketamine $2.5 \mathrm{mg} . \mathrm{kg}-1$ against midazolam $0.5 \mathrm{mg} \cdot \mathrm{kg}^{-1}$, had the same incidence of mask acceptance at induction $(70 \%$ in both arms) but with the MIKE group showed faster recovery (21.2 min, SD 6.6) than the midazolam group ( $29 \mathrm{~min}, \mathrm{SD} 6.3$ ). ${ }^{4}$ The incidence of vomiting was the same between the two groups (6.6\%), but the MIKE group had a greater incidence of hypersalivation $(6.6 \%$ vs. $0 \%$ ). Baygin et al., using midazolam $0.25 \mathrm{mg}^{\mathrm{kg}} \mathrm{kg}^{-1}$ and ketamine $3 \mathrm{mg} \cdot \mathrm{kg}^{-1}$ in comparison against midazolam $0.7 \mathrm{mg}^{\mathrm{kg}}{ }^{-1}$, reported higher quality sedation with MIKE with a similar recovery time to that of midazolam. ${ }^{6}$ Side-effects in the MIKE group included hypersalivation (53\%) and hallucinations (15\%). The midazolam group alone experienced bronchospasm (6.5\%), coughing (27\%) and hiccoughs (6.5\%). Postoperative nausea and vomiting were the same in both groups (25\%). In their 2004 trial Darlong et al., comparing midazolam 0.25 mg. $\mathrm{kg}^{-1}$ and ketamine $3 \mathrm{mg} . \mathrm{kg}^{-1}$ against midazolam $0.5 \mathrm{mg} \cdot \mathrm{kg}^{-1}$, found the same incidence of mask 
acceptance between the two groups but a faster emergence in the MIKE group (23 min, SD 5.6 vs. $35 \mathrm{~min}, \mathrm{SD} 11.7$ ) as compared to the midazolam alone group. ${ }^{8}$ There was no difference between the two groups in the incidence of postoperative nausea and vomiting $(25 \%)$ or hypersalivation $(0 \%)$. In the second arm of their 2011 trial Darlong et al. compared midazolam $0.25 \mathrm{mg}^{\mathrm{kg}} \mathrm{g}^{-1}$ and ketamine $3 \mathrm{mg}^{\mathrm{kg}}{ }^{-1}$ to midazolam $0.5 \mathrm{mg}^{\mathrm{kg}} \mathrm{kg}^{-1}$. The quality of sedation was the same between both groups at the time of mask acceptance, but recovery was much faster in the MIKE group than the midazolam alone group ( $22 \mathrm{~min}$, SD 5.7 vs. 36 min, SD 12.1 respectively). The MIKE group had a lower rate of postoperative nausea and vomiting (20\%) as compared to the midazolam alone group (35\%).

The analysis suggests that a MIKE regimen using a midazolam dose of between 0.25 and $0.3 \mathrm{mg}^{\mathrm{kg}}{ }^{-1}$ with a ketamine dose of between 2 and $3 \mathrm{mg} \cdot \mathrm{kg}^{-1}$ achieves higher quality sedation as compared to using midazolam 0.5 mg. $\mathrm{kg}^{-1}$ alone with a low incidence of side-effects and without prolonging recovery time.

\section{Discussion}

Anaesthetists frequently deal with paediatric patients who are uncooperative at induction of anaesthesia. This is not only an unpleasant and terrifying experience for the child but is also taxing for the parent and attending healthcare workers. Alleviation of this anxiety results in smoother and more elegant anaesthetic induction. ${ }^{1}$ Much of the preoperative anxiety experienced by children is related to their fear of parental separation, an unfamiliar hospital environment, the operation and related pain. A stressful induction of anaesthesia has been associated with long-term sequelae such as general anxiety, enuresis and temper tantrums, and it has been suggested that avoiding this anxiety may prevent these postoperative behavioural changes. ${ }^{1}$

Ketamine, an arylcyclohexylamine, produces dose-related analgesia, sedation and anaesthesia. It results in a dissociative state of anaesthesia characterised by profound analgesia and anaesthesia while the patient remains in a dose-dependent cataleptic state. In comparison to other anaesthetic agents, ketamine displays a relative preservation of airway reflexes and tone. ${ }^{15}$ Ketamine is known to be associated with psychomimetic effects such as nightmares, extracorporeal experiences and hallucinations. These effects are reduced by co-administration of midazolam. ${ }^{15}$ Combining oral ketamine and midazolam lowers the total dose of each drug resulting in less adverse effects. ${ }^{4}$

Midazolam, belongs to the group of benzodiazepines known for their anxiolytic characteristics mediated through $\mathrm{GABA}_{\mathrm{A}}$ receptors in the brain. They are commonly used as a premedication to produce dose-related sedation, anxiolysis, and anterograde amnesia. At the recommended oral premedication dose of $0.4-0.8 \mathrm{mg} \cdot \mathrm{kg}^{-1}$ they have very little depressant effects on the cardiovascular and respiratory systems. ${ }^{15}$ Recently, ADV6209, a $0.2 \%$ aqueous midazolam formulation which is formulated with a gamma-cyclodextrin complex to mask the bitter taste associated with oral midazolam syrup, has been approved in
Europe for paediatric sedation. ${ }^{16,17}$ The unpalatable intravenous formulation is masked with dextrose to allow voluntary oral administration in hospitals that do not have the oral formulation available. As has been shown, the combination of midazolam and ketamine is able to improve sedation quality while reducing side-effects. This combination is discussed in current guidelines on paediatric procedural sedation but they do not specifically recommend dosage ranges. ${ }^{18,19}$ This study, therefore, provides useful data that will assist the clinician in achieving optimal and safe sedation before anaesthesia. The study is limited by the bias inherent in each of the underlying trials, however, in general the quality of the included trials was high. The small total sample size of this literature review, as well as the small size of the individual trials is an important finding suggesting that additional work is required in this field before being able to draw firm conclusions. The small sample sizes inherent limit the generalisability of the result. We planned to conduct a meta-analysis, however, due to the wide variation in the composition of the sedation assessment tools and their use of unvalidated assessment tools, the authors decided that it would be inappropriate to conduct a meta-analysis. We have chosen to report our results as a narrative synthesis thereby forfeiting the benefit of generating a summary statistic for this analysis.

\section{Conclusion}

The analysis suggests trials using combinations of midazolam ( 0.25 to $0.3 \mathrm{mg} \cdot \mathrm{kg}^{-1}$ ) and ketamine ( 2 to $3 \mathrm{mg} \cdot \mathrm{kg}^{-1}$ ) provided higher quality sedation with a similar or better side-effect profile than midazolam $0.5 \mathrm{mg} \cdot \mathrm{kg}^{-1}$ alone, without prolonging recovery time.

\section{Ethics committee approval}

BREC ref no.: EXM444/18

\section{Conflict of interest}

The authors declare no conflict of interest.

\section{Funding source}

No funding was required.

\section{Plagiarism}

The article submitted to SAJAA, titled: Ketamine and midazolam as procedural sedation in children: A structured literature review and narrative synthesis, is the original work of Prishani Reddy, Marsha Ramburuth and Reitze Rodseth.

\section{ORCID}

P Reddy (iD https://orcid.org/0000-0003-3322-6084 R Rodseth (iD https://orcid.org/0000-0002-3779-7805 M Ramburuth (iD) https://orcid.org/0000-0002-9281-1470

\section{References}

1. Tan L, Meaken G. Anaesthesia for the uncooperative child. Continuing Education in Anaesthesia, Critical Care \& Pain. 2010;10(2):48-52. https://doi.org/10.1093/ bjaceaccp/mkq003.

2. Bozkurt P. Premedication of the pediatric patient - anesthesia for the uncooperative child. Current Opinion in Anaesthesiology. 2007;20(3):211-5. https://doi.org/10.1097/ACO.0b013e328105e0dd. 
3. Auden SM, Sobczyk WL, Solinger RE, Goldsmith LJ. Oral ketamine/midazolam is superior to intramuscular meperidine, promethazine, and chlorpromazine for pediatric cardiac catheterization. Anesth Analg. 2000;90(2):299-305. https://doi. org/10.1097/00000539-200002000-00011

4. Banerjee B, Bose A, Pahari S, Dan AK. A comparative study of paediatric oral premedication: midazolam, ketamine and low dose combination of midazolam and ketamine. J Indian Med Assoc. 2011;6(109)

5. Barkan S, Breitbart R, Brenner-Zada G, Feldon M, Assa A, et al. A double-blind, randomised, placebo-controlled trial of oral midazolam plus oral ketamine for sedation of children during laceration repair. Emergency Medicine Journal. 2014;31(8):649-53. https://doi.org/10.1136/emermed-2012-202189.

6. Baygin $\mathrm{O}$, Bodur $\mathrm{H}$, Isik B. Effectiveness of premedication agents administered prior to nitrous oxide/oxygen. European Journal of Anaesthesiology. 2010;27(4):341-6. https://doi.org/10.1097/EJA.0b013e3283313cdd.

7. Darlong V, Shende D, Singh M, Garg R, Pandey R, Punj J. Low- versus high-dose combination of midazolam-ketamine for oral premedication in children for ophthalmologic surgeries. Singapore Medical Journal. 2011;52(7):512-6.

8. Darlong V, Shende D, Subramanyam MS, Sunder R, Naik A. Oral ketamine or midazolam or low dose combination for premedication in children. Anaesthesia and Intensive Care. 2004;32(2):246-9. https://doi.org/10.1177\%2F03100 57X0403200214.

9. Funk W, Jakob W, Riedl T, Taeger K. Oral preanaesthetic medication for children: double-blind randomized study of a combination of midazolam and ketamine vs midazolam or ketamine alone. British Journal of Anaesthesia. 2000;84(3):335-40. https://doi.org/10.1093/oxfordjournals.bja.a013435.

10. Trabold B, Rzepecki A, Sauer K, Hobbhahn J. A comparison of two different doses of ketamine with midazolam and midazolam alone as oral preanaesthetic medication on recovery after sevoflurane anaesthesia in children. Paediatric Anaesthesia. 2002;12(8):690-3. https://doi.org/10.1046/j.1460-9592.2002.00945.x.

11. Moher D, Liberati A, Tetzlaff J, Altman DG. The PRISMA Group (2009). Preferred reporting items for systematic reviews and meta-analyses: The PRISMA
Statement. PLoS Med 6(6): e1000097. https://doi.org/10.1371/journal. pmed.1000097.

12. Kulikov AS, Sorokin VS, Lubnin A. Oral premedication with midazolam and ketamine in children with neurosurgical diseases. Anesteziologiia i reanimatologiia. 2010(1):6-10.

13. Astuto $M$, Disma N, Crimi E. Two doses of oral ketamine, given with midazolam for premedication in children. Minerva Anestesiologica. 2002;68(7-8):593-8.

14. Warner DL, Cabaret J, Velling D. Ketamine Plus midazolam, a most effective pediatric oral premedicant. Pediatric Anesthesia. 1995;5(5):293-5. https://doi. org/10.1111/j.1460-9592.1995.tb00307.x.

15. Milner A, Welch E. Applied pharmacology in anaesthesiology and critical care. South Africa: Medpharm Publications (Pty) Ltd; 2012.

16. Marçon F, Guittet C, Manso MA, Burton I, Granier L-A, Jacqmin $P$, et al. Population pharmacokinetic evaluation of ADV6209, an innovative oral solution of midazolam containing cyclodextrin. Eur J Pharm Sci. 2018;114:46-54. https://doi. org/10.1016/j.ejps.2017.11.030.

17. Mason KP, Seth N. Future of paediatric sedation: towards a unified goal of improving practice. British Journal of Anaesthesia. 2019;122(5):652-661. https:// doi.org/10.1016/j.bja.2019.01.025.

18. Practice Guidelines for Moderate Procedural Sedation and Analgesia 2018: A Report by the American Society of Anesthesiologists Task Force on Moderate Procedural Sedation and Analgesia, the American Association of Oral and Maxillofacial Surgeons, American College of Radiology, American Dental Association, American Society of Dentist Anesthesiologists, and Society of Interventional Radiology. Anesthesiology. 2018;128(3):437-79. https://doi. org/10.1097/ALN.0000000000002043.

19. Coté CJ, Wilson S, American Academy of Pediatrics, American Academy of Pediatric Dentistry. Guidelines for Monitoring and Management of Pediatric Patients Before, During, and After Sedation for Diagnostic and Therapeutic Procedures: Update 2016. Pediatrics. 2016;138(1). e20161212. https://doi. org/10.1542/peds.2016-1212. 